\title{
Studying the Impact of the Solar Activity on the Maximum Usable Frequency Parameter over Iraq Territory
}

\author{
Khalid A. Hadi, Aqeel Z. Aziz \\ (Department of Astronomt \& Space, College of Sciences / University of Baghdad, Iraq)
}

\begin{abstract}
In this study, the influence of the solar activity on the Maximum Usable Frequency (MUF) parameter has been achieved by adopting a monthly observed sunspots number for the years $2000 \& 2010$. The values of the MUF parameter has been calculated using the VOACAP international model between Baghdad city and many receiving stations which are distributed on different locations over Iraqi territory. The results of this study showed that the impact of the solar activity on the behavior of MUF parameter at year 2000 is more intense than that at the year of 2010.
\end{abstract}

Keywords: Ionospheric Parameters, Maximum Usable Frequency, Solar Activity, Solar Cycle.

\section{INTRODUCTION}

In the years 1920s and 1930s amateurs and professionals discovered HF communications. In the late '30s, many organizations were involved in the study of HF communications. A considerable effort was made in the U.S.A. and other countries. The Radio Propagation Unit of the U.S. Army Signal Corps provided a great deal of information and guidance on the phenomena of HF propagation in 1945. By 1948, a treatise of ionospheric radio propagation was published by the Central Radio Propagation Laboratory (CRPL) of the national Bureau of Standards. This document (NBS, Circular 462, 1948) outlined the state of the art in HF propagation. Techniques were included for: predicting the maximum usable frequencies (MUF); determining the MUF for any path at any time taking into account the various possible modes of propagation by combining theory and operational experiences; and estimating skywave field strength [1].

The Maximum usable frequency (MUF) is the highest frequency at which radio waves are returned to Earth by ionospheric refraction and which can be used to transmit over a particular path under given ionospheric conditions at a specific time, the median value of MUF working 50\% of the time specific time.

The MUF is used to determine the frequency that provides the optimum performance for the radio communications system. The basic of the MUF represents the highest frequency by which a radio wave can propagate between given terminals by ionospheric propagation alone. The MUF in particular varies greatly throughout the day, seasonally, location of terminals, orientation, and the solar activity.

The MUF is reflected from the maximum electron density within a given layer of the ionosphere, therefore the MUF must be statistically based on the electron density of ionosphere, so the frequencies higher than the MUF penetrate the ionosphere and continue into space, while frequencies lower than the MUF tend to refract in the ionosphere and return back to Earth [2].

The variability of ionospheric parameters has been studied from many researchers for example N. O. de Adler [et al., 1997] [3], N. Kawamura [et al., 2002] [4], R. P. Kane [2003] [5], C. Chen [et al., 2006] [6], E. A. Araujo-Pradere [et al., 2011] [7], Nuzhat Sardar [et al., 2012] [8]

\section{Radio Waves Communication}

Radio propagation is a term used to explain how radio waves behave when they are transmitted, or are propagated from one point on the Earth to another. The interaction of radio waves with the ionized regions of the atmosphere makes radio propagation more complex to predict and analyze than in free space. Different frequencies of radio waves have different propagation characteristics in the Earth's atmosphere, the ionosphere region the atmosphere enables high frequency $(\mathrm{HF})$ radio communications signals to be reflected, or more correctly refracted back to earth so that they can travel over great distances around the globe [9]. When HF signal is transmitted using sky wave propagation, over a given path there is a MUF which is determined by the state of the ionosphere in the vicinity of the reflection points the level of solar radiation angle or takeoff angle $(i)$, layer height $(h)$ and the length of the circuit $(D)$, as shown in figure (1). This result from the fact that as the MUF signals increases it will pass through more layers and communication is lost, because the MUF signals eventually traveling into outer space. As it passes through one layer it may be that then propagates over a greater distance than is required [10]. 


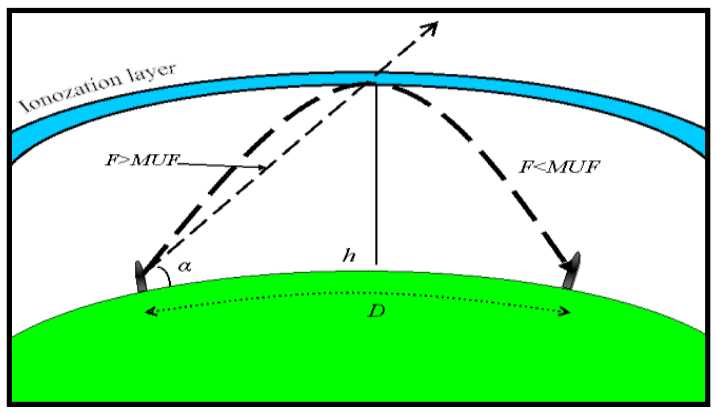

Fig. (1): Illustrated the skip-mode of MUF that occurs between two points [10].

Terrestrial communication at HF to long ranges has been in use for nearly 80 years. The mode flexibility and the capability of communication range, as well as complexity of intermediate relay stations. However, the ionosphere is highly variable in all time scales: within an hour, through the day, from season to season and with the 11-year solar cycle. In recent years it has become more difficult to find and retain skilled operators, and new procedures within the Radio-communication Bureau mean that there is no compatibility assessment prior to inclusion of assignments in the Master International Frequency Register. Thus it might be expected that the overall service quality would progressively degrade [11].

The World Radio communication Institute for Telecommunication Union (ITU) is established new models like (IONCAP, REC533 and VOACAP) to solute the problem of matching the HF system characteristics to the ionospheric channel variability. Automatically controlled radio systems evaluates the circuit performance during operation and change the operating frequency and other circuit parameters to predict the monthly median MUF values over the days of the month at that hour for the possible modes and other parameters [12].

\section{VOACAP International Model}

For many years, numerous organizations have been employing the High Frequency (HF) spectrum to communicate over long distances. It was recognized new communication systems were subject to marked variations in performance, and it was hypothesized that most of these variations were directly related to changes in the ionosphere. Considerable effort was made in the United States, as well as in other countries, to investigate ionospheric parameters and determine their effect on radio waves and the associated reliability of HF circuits [13]. In 1978, the Institute for Telecommunication Sciences of the National Telecommunications and Information Administration (NTIA/ITS) released for the U.S. Army a program developed by George Haydon, John Lloyd and Donald Lucas called the "Ionospheric Communications Analysis and Prediction" program, IONCAP for short.

In 1983 George Lane cleaned up and corrected IONCAP to retain all of the theory as put forth by Lloyd, Haydon and Lucas and developed a new model for the account of Voice of America Coverage Analysis Program (VOACAP). It is an ionospheric model predicting the expected performance of HF transmissions. It takes into account tens of parameters to support you in the planning and operation of long distance amateur traffic or broadcast transmissions [14]. Currently many HF broadcasts like Voice of America (VOA), British Broadcasting Corporation (BBC), Institute Telecommunication Union (ITU) and High Frequency Coordination Conference (HFCC), because the VOACAP model represents the best model for analysis the HF communication.

The VOACAP model predicts the long term operational parameters, such as maximum usable frequency (MUF), optimum traffic frequency (FOT), and lowest useful frequency (LUF), in terms of the probability of successful transmission for a particular circuit.

\section{Test and Results}

The goal of this research is to study the influence of solar activity on the behavior of the MUF parameter between two connection points over Iraqi territory.

The VOACAP model has been adopted in this work to calculate the monthly MUF parameter between two communication links for 24 hours over Iraqi zone. For this study, the monthly observed sunspots for years (2000) and (2010) have been selected, because the year 2000 represents the peak of the 23 solar cycle while the year 2010 represents the minimum of the 24 solar cycle. The behavior of monthly observed sunspots number for these years can be described in the figure (2):- 


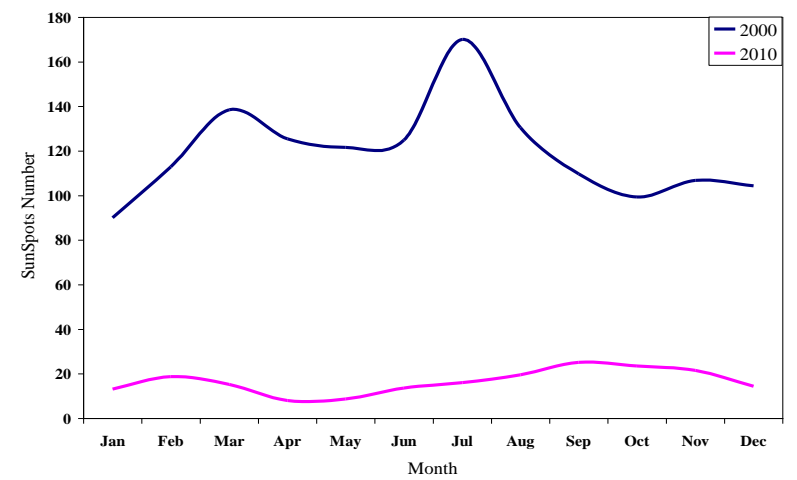

Fig. (2): Shows the monthly Sunspot Numbers (SSNs)

for the years $2010 \& 2000$.

In this study, Iraqi territory has been picked to represent the studied communication region by adopting the Capital Baghdad as a transmitting station and many thirty different locations have been represented as receiving stations which are located on different directions over Iraqi zone, as shown in figure (3):

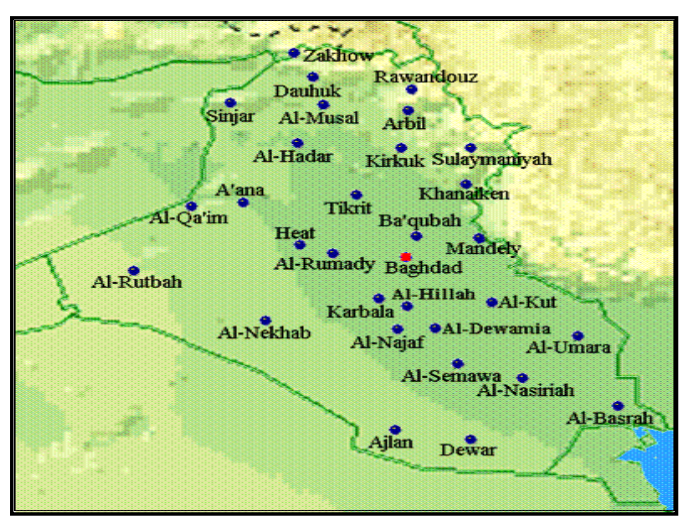

Fig. (3): Shows the transmitting and receiving stations. table (1):

The geographic locations (longitude and latitude) for selected receiving stations can be described in the

TABLE 1

Illustrate (Longitude and Latitude for selected receiving stations).

\begin{tabular}{|l|c|c|}
\hline \multirow{2}{*}{ Station name } & \multicolumn{2}{|c|}{ Location } \\
\cline { 2 - 3 } & Longitude (E) & Latitude (N) \\
\hline A'ana & 41.92 & 34.39 \\
\hline Ajlan & 44.27 & 30.04 \\
\hline Al-Basrah & 47.78 & 30.50 \\
\hline Al-Dewania & 44.93 & 31.00 \\
\hline Al-Hather & 43.72 & 35.58 \\
\hline Al-Hillah & 44.46 & 32.42 \\
\hline Al-Kut & 45.82 & 31.50 \\
\hline Al-Musal & 43.13 & 36.33 \\
\hline Al-Najaf & 44.33 & 31.98 \\
\hline Al-Nekhab & 42.27 & 32.15 \\
\hline Al-Qa'im & 42.05 & 34.37 \\
\hline Al-Rumady & 43.31 & 33.43 \\
\hline Al-Rutbah & 40.17 & 33.1 \\
\hline Al-Semawa & 45.28 & 31.32 \\
\hline Al-Umara & 47.17 & 31.85 \\
\hline Arbil & 44.52 & 36.18 \\
\hline Ba'qubah & 44.64 & 33.75 \\
\hline Dauhuk & 43.00 & 36.87 \\
\hline Dewar & 45.49 & 29.85 \\
\hline Heat & 42.8 & 33.63 \\
\hline
\end{tabular}




\begin{tabular}{|l|c|c|}
\hline Kirkuk & 44.38 & 35.47 \\
\hline Karbala & 44.03 & 32.60 \\
\hline Khanaiken & 45.38 & 34.8 \\
\hline Mandely & 45.6 & 33.73 \\
\hline Nasiriah & 46.26 & 31.04 \\
\hline Rawandouz & 44.55 & 36.61 \\
\hline Sinjar & 41.68 & 36.33 \\
\hline Sulaymaniyah & 45.48 & 35.5 \\
\hline Tikrit & 43.68 & 34.60 \\
\hline Zakhow & 42.7 & 37.3 \\
\hline
\end{tabular}

In this project the influence of solar activity for years (2000) and (2010) have been studied on the MUF parameter. Table (2) Shows analysis sample of MUF parameter values for years 2000 \& 2010 that have made using VOACAP model.

TABLE 2

Shows samples of the values of the MUF parameters.
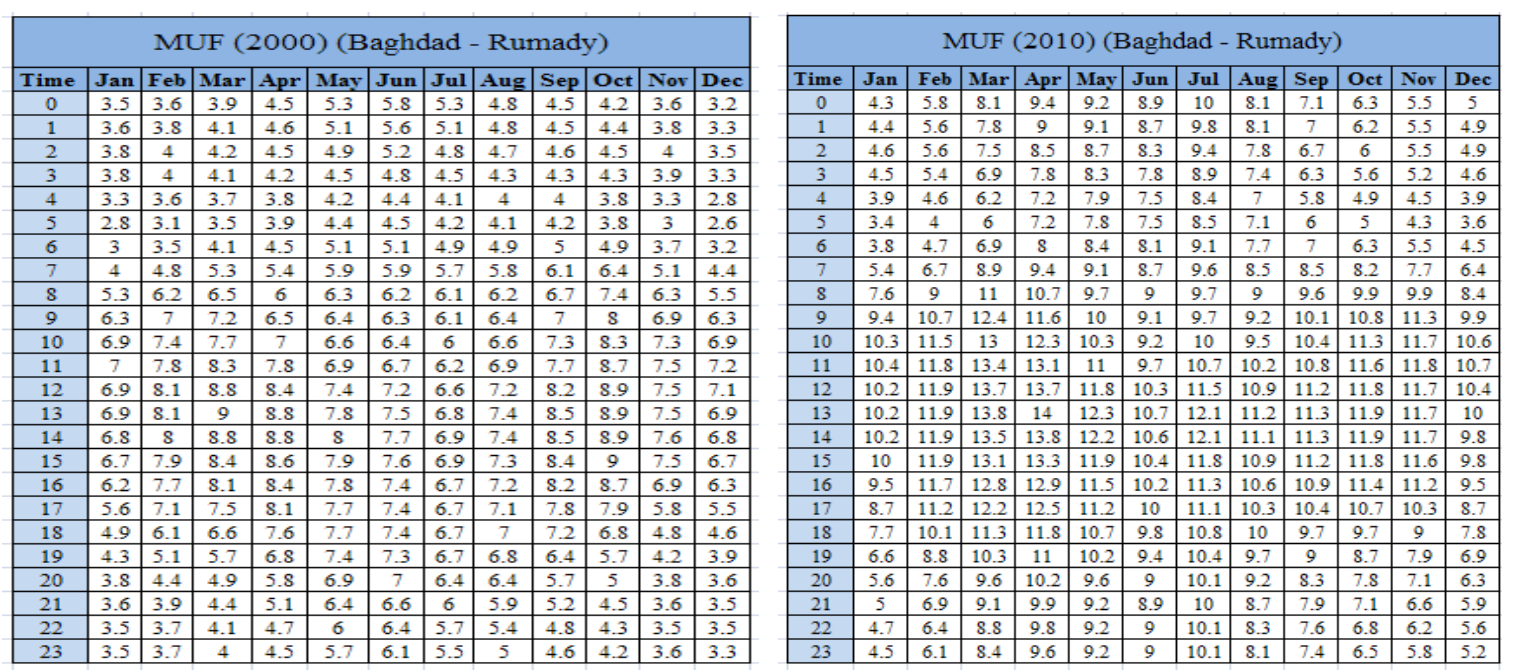

The effect of solar activity on the MUF parameter has been made for the selected locations which are distributed over Iraqi zone, figure (4): illustrate sample of the solar activity effect on the MUF parameter.
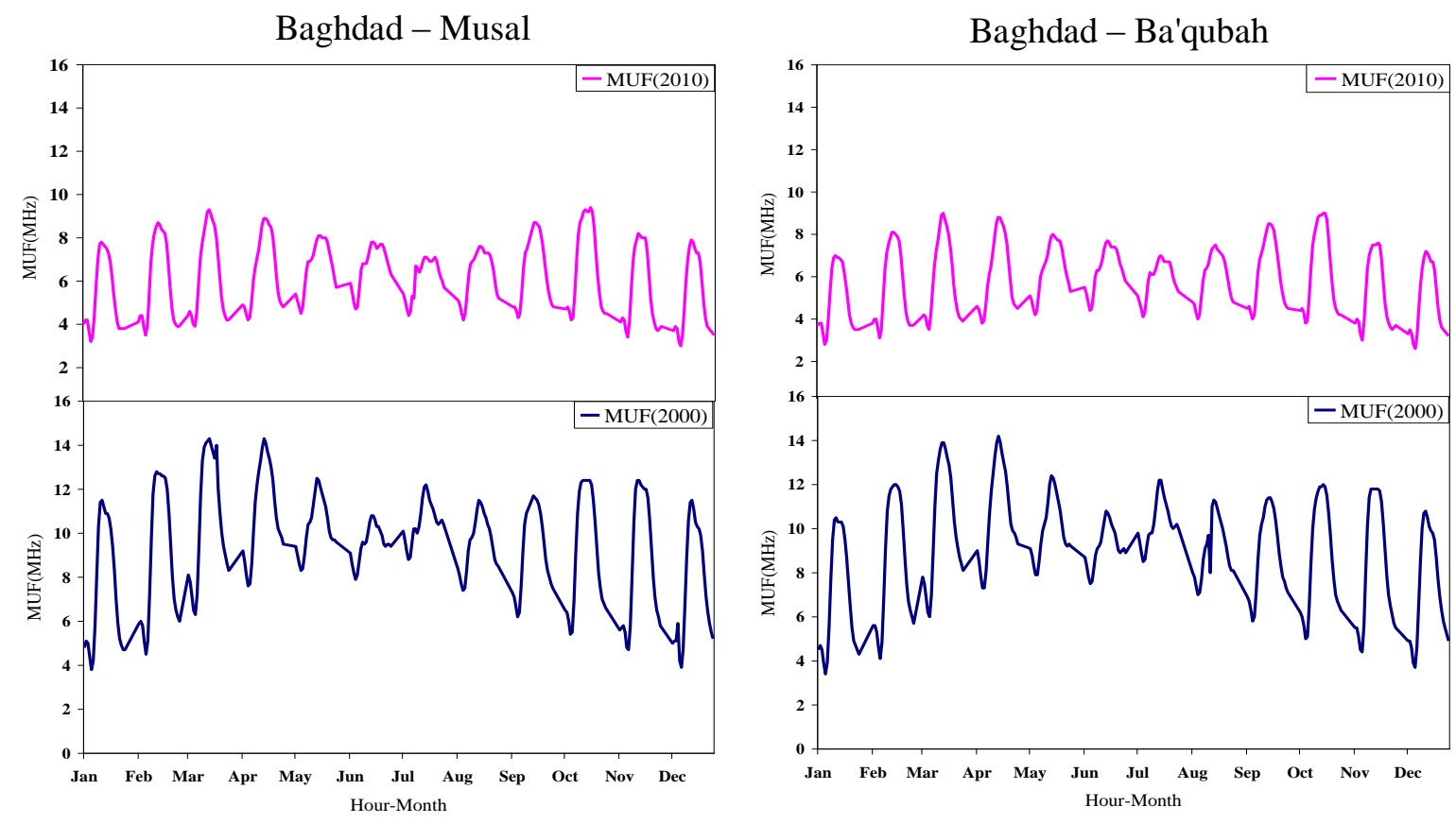

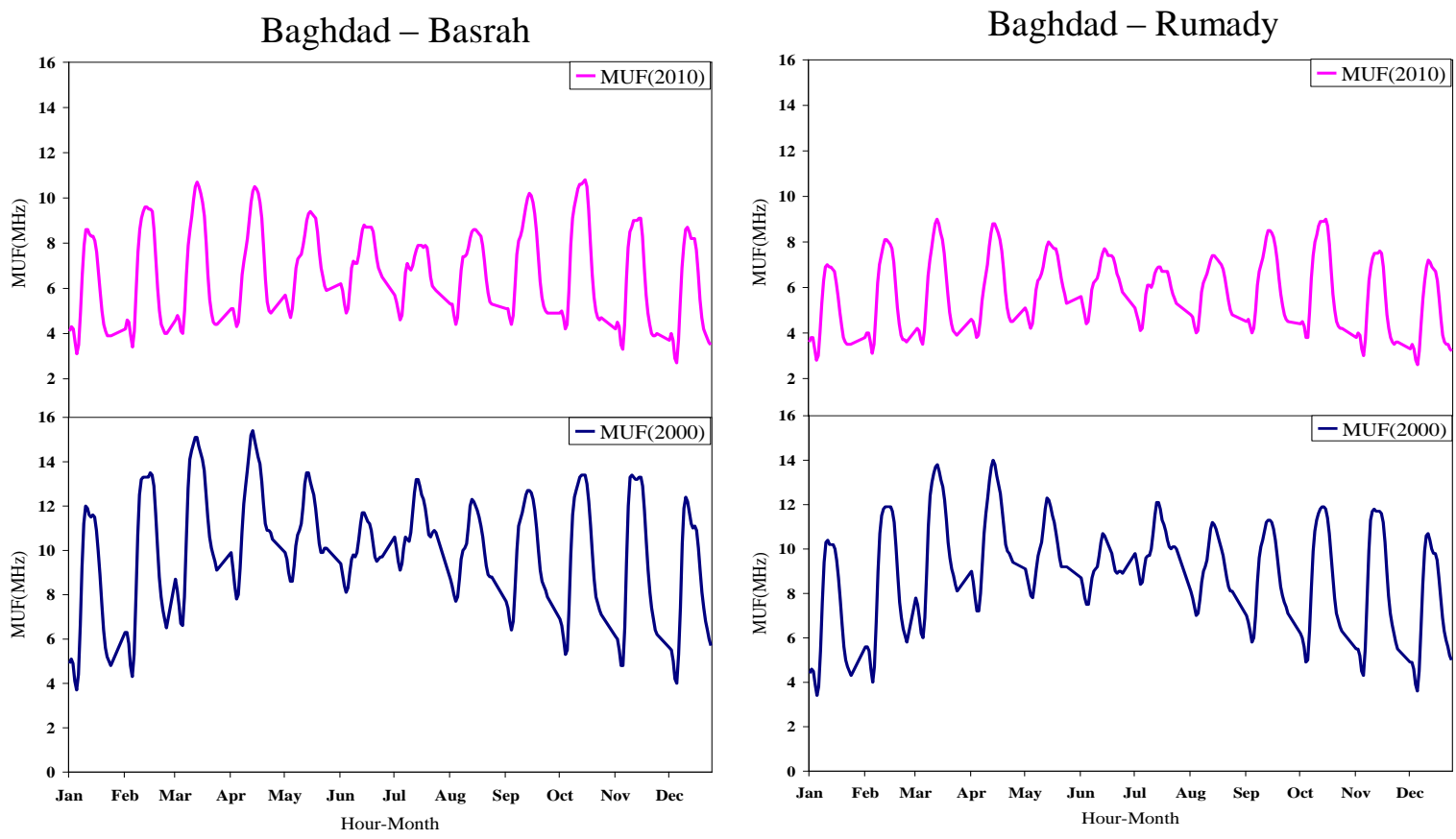

Fig. (4): shows the effect of solar activity on MUF parameter.

\section{Discussion and Conclusion}

In this research, the test for the impact of the solar activity on the MUF parameter values has been made depending on the dataset that have achieved from the execution of the VOACAP international communication model over Iraqi territory.

The influence of the solar activity on the MUF parameter has been studied for different locations around Baghdad city. According to the result of this study, the impact of the solar activity for year 2000 showed stronger influence on the values of the MUF parameter than the effect of solar activity for the year of 2010 that may due to the variation of the sunspots number, as shown in figure (4).

From the above discussion, it can be concluded that the effect of the solar activity on the behavior of MUF parameter at year 2000 is more intense than the effect of solar activity on the behavior of MUF parameter at year 2010.

\section{References}

[1]. N. M. MASLIN, HF Communications: A Systems Approach. Plenum Press, New York, United States of America and Pittman Publishing United Kingdom, 1987.

[2]. MIL-STD-188-141B Interoperability and Performance standards for Medium and High Frequency Radio Systems, Department of Defense Interface Standard, Standardization Document Order Desk. PA 19111-5094. 700 Robbins Ave. Building 4D, Philadelphia, United States of America, March 1999.

[3]. N. O. de Adler, A. G. Elías \& J. R. Manzano, Solar cycle length variation: Its relation with ionospheric parameters. Journal of. Atmos Solar-Terr Phys, 1997, 59: 159-162

[4]. Kawamura, S., Balan, N., Otsuka, Y., \& Fukao, S.,Annual and semiannual variations of the mid-latitude ionosphere under low solar activity, J. Geophys. Res.,107 (A8), 1166, 2002.

[5]. R P. Kane, Solar EUV and ionospheric parameters: A brief assessment, Adv Space Res, 32, 2003, 1713-1718.

[6]. C. Chen, Z. S. Wu, S. J. Sun, Z. H. Ding \& Z. W. Zhao, MUF variability at Haikou, China, paper presented to International Symposium on Antennas, Propagation and EM Theory - ISAPE, 2008, DOI: 10.1109/ISAPE.-2008.4735232.

[7]. Araujo-Pradere, E. A., R. Redmon, M. Fedrizzi, R. Viereck, \& T. J. Fuller-Rowell, Some characteristics of the ionospheric behavior during the solar cycle 23-24 minimum, Journal of Sol. Phys., doi:10.1007/s11207-011-9728-3, in press, 2011.

[8]. Nuzhat Sardar, Anup K Singh1, Anju Nagar2, S.D Mishra3 \& S.K. Vijay, Study of Latitudinal variation of Ionospheric parameters -A Detailed report, Journal of. Ind. Geophys. Union, 16 (3), 2012, 113-133.

[9]. FED-STD-1045 Telecommunications: HF Radio Automatic Link Establishment and FEDSTD- 1045A, October 1993.

[10]. J. M. Goodman, J. W. Ballard and E. Sharp, A long-term investigation of the HF communication channel over middle- and high latitude paths. Radio Sci., 32(4), 1997, 1705-1715.

[11]. J. M. Goodman, HF Communications: Science \& Technology. Van Nostrand Reinhold, New York, United States of America. (Copyright transfer 2001: JMG Associates, Alexandria VA 22308, United States of America), 1992.

[12]. M. Darnell, Channel evaluation techniques for dispersive communication paths. Communication Systems and Random Process Theory. Skwirzynski J. K., Sijthoff and Noordhoff, the Netherlands, 1982.

[13]. L. R. Teters, J.L. Lloyd, G.W. Haydon \& D.L. Lucas, Estimating the Performance of Telecommunication Systems Using the Ionospheric Transmission Channel, Institute for Telecommunication Sciences NTIA Report 83-127, July 1983.

[14]. Sweeney N.M., F.J. Rhoads \& L.M. DeBlasio, Voice of America coverage analysis program (VOACAP) user's manual, VOA B/ESA/TR-02-93, USIA/SW/CK-93/001A,PB93155174INZ, 1993. 